\title{
Assessing the clinical utilization of tranexamic acid by paramedics for patients with major trauma (ACUTE)
}

\author{
Daniel Wong ${ }^{1} \cdot$ Gloria Su ${ }^{2} \cdot$ Vincent H. Mabasa ${ }^{2} \cdot$ John M. Tallon ${ }^{3,4} \cdot$ Joe Acker $^{3} \cdot$ Wilson Wan $^{3} \cdot$ Sandra Jenneson $^{3}$
}

Received: 3 July 2020 / Accepted: 21 October 2020 / Published online: 4 January 2021

(c) Canadian Association of Emergency Physicians (CAEP)/ Association Canadienne de Médecine d'Urgence (ACMU) 2021

\begin{abstract}
Objectives This study aimed to characterize the clinical utilization of tranexamic acid (TXA) by paramedics in British Columbia (BC) for acute major trauma and to quantify the percentage of patients who received TXA among those who met the indications for administration.

Methods A quality assurance review of eligible trauma patients across the province was performed using a convenience sample. Trauma patients between April 1, 2016 and March 31, 2017 with suspected or actual hemorrhage were selected if they met inclusion criteria (systolic blood pressure $<90 \mathrm{~mm} \mathrm{Hg} \pm$ heart rate $>120$ beats per minute) and exclusion criteria (age $<16$ years, injuries exclusively to the extremities).

Results 35 of the 100 eligible patients assessed in this review received a dose of TXA from paramedics. All 35 of the patients received TXA within 180 min of injury regardless of their original location of injury in BC (mean: 50 min; range: $15-140 \mathrm{~min})$.

Conclusions $35 \%$ of eligible patients identified in this study received TXA, which is an improvement over rates cited by previous Canadian literature. With further education opportunities for paramedics in BC and other EMS systems, there is potential to continue improving pre-hospital TXA administration rates.
\end{abstract}

Keywords Tranexamic acid · Paramedic $\cdot$ Pre-hospital $\cdot$ Trauma $\cdot$ Emergency medicine $\cdot$ Emergency medical service

\section{Résumé}

Objectifs Cette étude visait à caractériser l'utilisation clinique de l'acide tranexamique (TXA) par les ambulanciers paramédicaux de la Colombie-Britannique pour les traumatismes aigus majeurs et à quantifier le pourcentage de patients qui ont reçu du TXA parmi ceux qui répondaient aux indications d'administration.

Méthodes Un examen de l'assurance qualité des patients traumatisés admissibles dans toute la province a été effectué à l'aide d'un échantillon de commodité. Les patients traumatisés entre le 1er avril 2016 et le 31 mars 2017 présentant une hémorragie suspectée ou réelle ont été sélectionnés s'ils répondaient aux critères d'inclusion (pression artérielle systolique $<90 \mathrm{~mm}$ $\mathrm{Hg} \pm$ fréquence cardiaque $>120$ battements par minute) et aux critères d'exclusion (âge $<16$ ans, blessures exclusivement aux extrémités).

Electronic supplementary material The online version of this article (https://doi.org/10.1007/s43678-020-00040-4) contains supplementary material, which is available to authorized users.

Daniel Wong

daniel.wong@fraserhealth.ca

1 Pharmacy Department, Royal Columbian Hospital, 330 E

Columbia St, New Westminster, BC V3L 3W7, Canada

2 Burnaby Hospital, Burnaby, BC, Canada

3 BC Emergency Health Services, Vancouver, BC, Canada

4 Department of Emergency Medicine, Dalhousie University, Halifax, NS, Canada 
Résultats 35 des 100 patients admissibles évalués dans le cadre de cet examen ont reçu une dose de TXA des ambulanciers paramédicaux. Les 35 patients ont tous reçu du TXA dans les 180 min suivant la blessure, quel que soit le lieu de leur blessure initiale en Colombie-Britannique (moyenne: $50 \mathrm{~min}$; intervalle: 15 à $140 \mathrm{~min}$ ).

Conclusions 35\% des patients admissibles identifiés dans le cadre de cette étude ont reçu du TXA, ce qui représente une amélioration par rapport aux taux cités dans les publications canadiennes précédentes. Grâce aux possibilités de formation continue pour les ambulanciers en Colombie-Britannique et dans d'autres systèmes d'Aide médicale urgente (AMU), il est possible de continuer à améliorer les taux d'administration de la TXA en milieu préhospitalier.

\section{Clinician's capsule}

What is known about the topic?

Although TXA administration in acute major trauma within 3 hours of injury reduces mortality, Canadian EMS administration rates are low.

\section{What did this study ask?}

How frequently do paramedics in British Columbia administer TXA to eligible patients in the pre-hospital setting?

\section{What did this study find?}

This health records review found that $35 \%$ of TXAeligible patients received a dose from paramedics.

\section{Why does this study matter to clinicians?}

Identification of areas for improvement and paramedic education may increase TXA administration rates, thereby optimizing patient outcomes.

\section{Introduction}

Tranexamic acid (TXA) is a recommended antifibrinolytic agent used to treat trauma patients with hemorrhage [1-4]. CRASH-2 found mortality benefit with TXA if given within $180 \mathrm{~min}$ of injury, but also noted increased risk for death due to bleeding if given after this window [2,3]. Subsequently, CRASH-3 suggested that TXA also reduces head injuryrelated deaths in patients with mild-moderate traumatic brain injury [5].

With emerging evidence of TXA's time-sensitive benefits, paramedics have the opportunity to administer TXA before arrival to the hospital, especially in remote communities. In turn, TXA can be administered sooner within the 180-min window while allowing hospitals to concentrate on other aspects of care [6,7].

BC Emergency Health Services (BC EHS) is the sole pan-provincial provider of EMS in British Columbia (BC). In 2014, BC EHS added TXA to the scope of practice of several specific paramedic certification levels $[1,6,7]$.
However, a review of a trauma center in $\mathrm{BC}$ revealed that only $19 \%$ of their eligible patients received a dose of TXA from paramedics [8]. To better characterize how paramedics use TXA across the province, our study aimed to quantify the percentage of eligible patients who received TXA in the pre-hospital setting.

\section{Methods}

\section{Study design and time period}

A quality assurance health records review was performed looking at BC EHS charts across the province. Research ethics approval was obtained from the University of British Columbia Clinical Research and Fraser Health Research Ethics Boards, and BC Trauma Registry.

\section{Data collection and analysis}

Provincial trauma cases are recorded in the BC Trauma Registry. They were all patients injured within the province, aided by paramedics, and brought to a hospital. All cases recorded between April 1, 2016 and March 31, 2017 were screened for inclusion and exclusion criteria. Patients with actual or suspected hemorrhage were included if they had a systolic blood pressure under $90 \mathrm{~mm} \mathrm{Hg}$ or a heart rate over 110 beats per minute, or both as per CRASH-2's inclusion criteria [2]. Patients were excluded if under 16 years of age, or they sustained injuries exclusively to the extremities, as standard of practice is to use a tourniquet.

Patients were then sequentially numbered and a computer random number generator was used to select for review. The data collector reviewed patient records and determined their eligibility based on suspicion or presence of actual hemorrhage [2]. To maintain consistency, discrepancies were discussed with another reviewer until an agreement was reached. When deemed eligible, data were then collected from the paramedics' charts as well as from the BC Trauma Registry's database. Eligible cases were reviewed until a convenience sample of 100 was attained.

Simple descriptive statistics were applied to assess baseline data as well as primary and secondary outcomes. 


\section{Outcome measures}

The primary outcome was the percentage of eligible patients who received pre-hospital TXA. Secondary outcomes included: TXA regimen administered; 28-day mortality; occurrence of deep vein thrombosis, pulmonary embolism, myocardial infarction, or stroke during subsequent hospital admission; percentage of eligible patients who received TXA based on highest level of paramedic in attendance; durations of time between injury and paramedic arrival, TXA treatment, and first hospital arrival; durations of time between injury and TXA treatment based on geographical location; and lastly, occurrence of patients receiving TXA despite contraindications or lack of indication (administration $>3 \mathrm{~h}$ after injury).

\section{Results}

Of the 100 patients, 21 were female and the average age was 45.3 years (Appendix A). The TXA group was notably younger. Most patients were included for tachycardia rather than hypotension. The TXA group had a higher mean injury severity score and more patients with hypotension.
Overall, 35 of 100 eligible patients were administered TXA. Among them, $80 \%$ received the standard regimen-1 g given intravenously over $10 \mathrm{~min}$ (Table 1) [2]. Other regimens were likely documentation errors. The mean time between injury and TXA administration was $50 \mathrm{~min}$, with the longest time being $140 \mathrm{~min}$. On average, patients who received TXA arrived at their first hospital in $78 \mathrm{~min}$ compared to $64 \mathrm{~min}$ for those without a dose.

A smaller proportion of patients in the TXA group died (6\%) versus the no-TXA group (11\%). No myocardial infarctions or strokes were noted in any of the patients.

More patients receiving TXA had a paramedic of higher certification level in attendance compared to those who did not receive TXA.

\section{Discussion}

In our study of trauma patients across BC, $35 \%$ of eligible patients received a dose of TXA in the pre-hospital setting. This rate is higher than others cited in previous studies. A centre in BC found a pre-hospital administration rate of $19 \%$ for their patients, while another centre in Ontario had an intra-hospital administration rate of $27 \%[8,9]$. There is still potential to further increase administration rates, but some

Table 1 Secondary outcomes

\begin{tabular}{lll}
\hline & TXA $(n=35)$ & No TXA $(n=65)$ \\
\hline Dose and regimen administered, $n(\%)$ & & \\
1 g IV over 10 min & $28(80 \%)$ & - \\
Other regimens & $5(14 \%)$ & - \\
Not specified & $2(6 \%)$ & - \\
Received TXA despite contraindication(s) or lack of indication, $n(\%)$ & & - \\
Administration $>3$ h after injury & $0(0 \%)$ & - \\
History of thrombosis & $0(0 \%)$ & $7(11 \%)$ \\
Total mortality at 28 days, $n(\%)$ & $2(6 \%)$ & $2(3 \%)$ \\
Total thrombosis events, $n(\%)$ & & $2(3 \%)$ \\
Deep vein thrombosis (DVT) & $3(9 \%)$ & $1(2 \%)$ \\
Pulmonary embolism (PE) & $1(3 \%)$ & $32(49 \%)$ \\
Highest level of paramedic in attendance, $n(\%)^{\mathrm{a}}$ & & $22(34 \%)$ \\
Primary care paramedic (PCP) & $0(0 \%)$ & $10(15 \%)$ \\
Primary care paramedic with IV endorsement (PCP IV) & $5(14 \%)$ & $23[2-165]$ \\
Advanced care paramedic (ACP) & $20(57 \%)$ & $64[10-496]$ \\
Critical care paramedic (CCP) & $10(29 \%)$ & - \\
Minutes between injury and paramedic arrival, mean [range] & $22[4-97]$ & - \\
Minutes between injury and first hospital arrival, mean [range] & $78[25-253]$ & - \\
Minutes between injury and tranexamic acid, mean [range] & $50[15-140]$ & - \\
Sorted by Greater Vancouver/Victoria $(n=17)$ & $33[15-87]$ & - \\
Sorted by Vancouver Island $(n=2)$ & $71[28-115]$ & - \\
Sorted by Interior BC $(n=13)$ & $69[19-140]$ & - \\
Sorted by Northern BC $(n=3)$ & $49[32-83]$ & - \\
\hline
\end{tabular}

${ }^{\mathrm{a}} \mathrm{CCP}$ is the highest paramedic certification level in $\mathrm{BC}$, followed by ACP, then PCP IV 
factors may limit the ability to give TXA such as poor intravenous accessibility, time constraints from heavy workloads, or short trips to the hospital. Longer trips to the hospital may allow for more time for paramedics to administer TXApatients who received TXA, on average, arrived at a hospital 14 min later.

We noted that no patients received TXA beyond the 180min window $[2,3]$. The longest time it took to administer TXA after injury was $140 \mathrm{~min}$, which was documented in interior BC. These results are reassuring in that patients receiving TXA were treated within the recommended time frame, regardless of location, improving their chances for survival [2-5].

From a quality assurance perspective, the observed association between higher paramedic certification levels with greater rates of TXA administration highlights a potential gap in training regarding TXA and its indication in trauma. This association, however, may be confounded by the likelihood that paramedics of higher certification levels are predisposed to scenarios with more trauma and more overt indications for TXA.

This study is limited by its design as a health records review with a relatively small sample size across the province. As a result, we were unable to evaluate the potential mortality difference between the two groups or assess the safety outcomes associated with TXA. In addition, because nearly all patients with isolated head injuries were not given TXA, our observed administration rate appears low, suggesting an opportunity for education after CRASH-3's publication [5].

Based on the existing literature, this is the first study of its kind to focus solely on pre-hospital utilization of TXA. In light of TXA's implementation into paramedics' scope of practice, this quality assurance study provides the first province-wide overview of when and how paramedics have been administering it, and whether TXA administration has differed in the diverse communities of BC [3]. The next step to improving administration rates is to determine appropriate interventions and then evaluate their effects in a future study.

\section{Conclusion}

Among a sample of eligible patients assessed in this study, only $35 \%$ of major trauma patients in the EMS phase of care received a dose of TXA. With increasing evidence supporting the use of TXA in trauma patients, it is paramount that EMS administration rates improve [2-7].

Acknowledgements The authors would like to acknowledge Julie Wei for her assistance with this study.

Funding This research received no specific grant from any funding agency, commercial or not-for-profit sectors.

\section{Compliance with ethical standards}

Conflict of interest The authors declare that they have no conflict of interest.

\section{References}

1. Trauma Management-Intervention Guidelines [Internet]. BCEHS Handbook. 2020 [cited 31 August 2020]. Available from: https ://umbraco.bcas.ca/treatment-guidelines/adult-guidelines/major -trauma/trauma-management/trauma-management-interventionguidelines/

2. Shakur H, Roberts I, Bautista R, Caballero J, Coats T, Dewan Y, With CRASH-2 trial collaborators, et al. Effects of tranexamic acid on death, vascular occlusive events, and blood transfusion in trauma patients with significant haemorrhage (CRASH-2): a randomised, placebo-controlled trial. Lancet. 2010;376(9734):23-32.

3. Roberts I, Shakur H, Afolabi A, Brohi K, Coats T, Dewan Y, With CRASH-2 trial collaborators, et al. The importance of early treatment with tranexamic acid in bleeding trauma patients: an exploratory analysis of the CRASH-2 randomised controlled trial. Lancet. 2011;377(9771):1096-1101.e2.

4. Morrison J, Dubose J, Rasmussen T, Midwinter M. Military application of tranexamic acid in trauma emergency resuscitation (MATTERs) study. Arch Surg. 2012;147(2):113.

5. The CRASH-3 trial collaborators. Effects of tranexamic acid on death, disability, vascular occlusive events and other morbidities in patients with acute traumatic brain injury (CRASH-3): a randomised, placebo-controlled trial. Lancet. 2019;394:1713-23.

6. Tallon JM. Trauma systems and emergency medical services: the missing link for tranexamic acid utilization in major trauma. CJEM. 2018;20(2):167-9.

7. El-Menyar A, Sathian B, Asim M, Latifi R, Al-Thani H. Efficacy of prehospital administration of tranexamic acid in trauma patients: a meta-analysis of the randomized controlled trials. Am J Emerg Med. 2018;36:1079-87.

8. Ng M, Perrott J, Burgess S. Evaluation of tranexamic acid in trauma patients: a retrospective quantitative analysis. Am J Emerg Med. 2018;37:444-9.

9. Ghawnni A, Coates A, Owen J. Compliance of tranexamic acid administration to trauma patients at a level-one trauma centre. CJEM. 2017;20(02):216-21. 